\title{
Movement and Distribution of House Flies (Diptera: Muscidae) Between Habitats in Two Livestock Farms
}

\author{
T. J. LYSYK ${ }^{1}$ AND R. C. AXTELL \\ Department of Entomology, North Carolina State University, \\ Raleigh, North Carolina 27695-7613
}

\begin{abstract}
J. Econ. Entomol. 79: 993-998 (1986)
ABSTRACT House fly, Musca domestica L., movement between breeding sites (dairies and poultry houses) and into surrounding habitats (buildings, fields, and pastures) was measured by releasing marked flies in poultry houses and dairies at two farms. Relative density of wild and marked flies was greater in the dairy and poultry houses than in other habitats at similar distances from the release areas. Calculated proportions of wild flies in each habitat were greatest in the dairies and poultry houses; averages of 25 and $36 \%$ of the wild populations were estimated to be in the other habitats. After 5 days, an average of 60 and $53 \%$ of marked flies released in the poultry houses remained there, $13 \%$ moved to the dairies at both farms, and 27 and $34 \%$ moved from the poultry houses to the nonbreeding habitats. An average of 56 and $73 \%$ of the marked flies released in the dairies remained there after 5 days, while 8 and $10 \%$ moved into the poultry houses, and 34 and $19 \%$ moved from the dairies into the nonbreeding habitats at both farms.
\end{abstract}

KEY WORDS Musca domestica, movement, habitats, poultry houses, dairies

STUdies OF dispersal of the house fly, Musca domestica $\mathrm{L}$., have focused on determining its range of flight (Parker 1916, Bishop \& Laake 1919, Lindquist et al. 1951, Ranade 1956), movement from breeding areas to urban areas (Schoof et al. 1952, Quarterman et al. 1954a, Schoof \& Siverly 1954a,b, Oda 1966), or between breeding areas located on different farms (Quarterman et al. 1954b, Hanec 1956, Wada \& Oda 1963, Morris \& Hansen 1966, Pickens et al. 1967). These reports indicate that house flies fly up to $20 \mathrm{~km}$ from a release point; however, few individuals moved $>1.6 \mathrm{~km}$ from a release point and movement was oriented toward unsanitary sites.

These studies have emphasized the importance of community efforts toward fly control. However, major fly breeding occurs in confined-livestock rearing facilities and fly control is the responsibility of the producer. Therefore, the degree of fly movement between and around confined-livestock facilities is important to the design of fly management programs. Integrated fly control procedures have been developed for poultry rearing facilities and have emphasized reducing insecticide applications, providing proper manure management, and enhancement of naturally occurring control agents (Axtell 1970). In dairies, fly control is achieved primarily through sanitation (manure removal) and insecticides.

House flies can develop resistance to insecticides shortly after introduction (Denholm et al. 1983,

${ }^{1}$ Current address: Can. For. Serv., Great Lakes Forest Research Center, P.O. Box 490, Saulte Ste. Marie, Ontario P6A 5M7 Canada.
MacDonald et al. 1983). Immigration of susceptible individuals into a treated area and the presence of areas that receive no insecticidal treatments (refugia) are believed to be important in delaying the development of insecticide resistance (Georghiou \& Taylor 1977a, Tabashnik \& Croft 1982). Since dairies and poultry houses are often located near each other either on the same or adjacent farms, and house flies breed freely in both systems, this study was conducted to describe the distribution of house flies on farms with both types of animal production facilities and to examine movement of flies between the two facilities and into nearby habitats.

\section{Materials and Methods}

Farm Habitats. Release/recapture experiments were conducted on two farms in North Carolina from May to September 1983. Farm A was located in Alamance County, N.C., and contained a dairy, poultry houses, miscellaneous storage buildings, pastures, and ungrazed fields. The dairy and poultry houses were ca. $100 \mathrm{~m}$ apart, with storage buildings and fields between them. The dairy habitat covered ca. 0.17 ha and consisted of a milking parlor, two silos, covered stalls, and an open yard with a central roofed feed trough. About $40 \mathrm{Hol}-$ stein cattle were maintained and fed in the yard. Manure removal was sporadic and rarely complete, and large amounts of manure and spilled feed accumulated in the yard. The pasture area consisted of ca. 3.02 ha of grassland continuously grazed throughout the summer by cattle, in contrast to the ca. 1.70 ha of field area, which was ungrazed open land. The poultry houses covered 
ca. 0.72 ha and consisted of two wide-span ( $12 \mathrm{~m}$ by $95 \mathrm{~m}$ ) and two open-sided, narrow-style (3.7 m by $95 \mathrm{~m}$ ), caged-layer poultry houses. The widespan houses had eight rows of two-tiered cages (two to three birds per cage) suspended $1 \mathrm{~m}$ above a concrete floor and separated by four walkways. The narrow houses were open-sided structures with two rows of two-tiered cages (two to three birds per cage) suspended $1 \mathrm{~m}$ above a dirt floor the length of the house on either side of a central concrete walkway. Manure in all houses was removed 1 week before the first release of marked flies at this farm and accumulated beneath the cages throughout the remainder of the season. Buildings were spread over ca. 1.06 ha and consisted of 13 wooden frame structures used for egg washing, mechanical work, and equipment storage.

Farm B was located in Chatham County, N.C., $12.9 \mathrm{~km}$ WSW of Farm A, and also had a dairy, poultry house, buildings, field, and pastures. The dairy and poultry house were ca. $120 \mathrm{~m}$ apart, with pasture between them. The dairy covered 0.56 ha and consisted of an open yard with a central feed trough and a barn with a milking parlor and indoor stalls. The yard was cleaned daily and manure moved to a lagoon for decomposition. Approximately 80 Holstein cattle were maintained, and these were let out to pasture daily. The highrise, caged-layer poultry house covered 0.21 ha ( 12.5 by $120 \mathrm{~m}$ ). Birds were housed on the upper floor in eight rows of two-tiered cages (two to three birds per cage) separated by five walkways. Manure accumulated on the ground ca. $4 \mathrm{~m}$ below the cages, and was partially cleaned out 3 weeks before the first release of marked flies in this farm. The buildings were four sheds ( 3.7 by $115 \mathrm{~m}$ ) covering 0.66 ha and were used for storing round hay bales. Pastures covered ca. 2.37 ha; ungrazed fields covered ca. 1.89 ha.

Marking Technique. The distribution and dispersal of marked flies were examined on both farms in a series of mark/release/recapture experiments from May to September 1983. House flies used for marking and releasing were obtained from a colony started with wild flies collected from a poultry house in Wake County, N.C., the previous fall. Adults were kept in screen cages and fed milk and sugar. Larvae were reared in a fly-rearing medium (Ralston Purina, St. Louis, Mo.)/yeast/water (CSMA medium) mixture. Pupae were separated from the medium with a forced air blower; ca. 22,000 pupae for each release site and date were collected (based on the weight of an aliquot sample of 500 pupae) and held for emergence in eight screen cages (11.6 liters). Flies were fed a solution of milk and $10 \%$ sucrose in water.

Flies were marked $1 \mathrm{~h}$ before release. Cold-immobilized flies were sprayed with a fine mist of either 2.5\% Calco red oil-soluble dye (American Cyanamid, Bound Brook, N.J.) in acetone (Quarterman et al. 1954a) or $6 \%$ phenolphthalein in acetone (Peffly \& LaBrecque 1956). When flies were arranged on white blotting paper and several drops of acetone followed by several drops of $1 \% \mathrm{NaOH}$ were placed on each fly, a red ring formed around flies marked with the red dye, and the color purple indicated that the fly had been marked with phenolphthalein. These dyes were chosen because earlier tests indicated that they did not affect survival or capture of flies with the traps used in this study.

Flies were transported to the release sites in an air-conditioned vehicle, and all releases were made before 1100 hours on the day of release. Approximately 20,000 flies marked with red dye were released in the dairy on Farm A and ca. 20,000 flies marked with phenolphthalein were released throughout the central, wide-span poultry house at Farm A on 30 May, 20 June, 11 July, and 1 and 22 August 1983. Releases were made at each site by opening cages slightly and carrying them throughout the dairy and poultry house until all flies had left the cages. Similarly, ca. 20,000 flies marked with red dye and 20,000 marked with phenolphthalein were released throughout the dairy and poultry house, respectively, at Farm B on 20 June, 11 July, and 1 and 29 August 1983.

Recapture Technique. Recaptures of marked flies at each farm were made starting the day after release to allow flies adequate time to move and to avoid excessive sampling of flies at the release areas. Sampling was conducted for a 3-day period using modified baited jug-traps (Burg \& Axtell 1984). Each trap was a 2.5-liter plastic pail with three holes ( $3.5 \mathrm{~cm}$ diam) cut in the side and baited with $25 \mathrm{~g}$ of fly bait (Improved Golden Malrin) containing $1 \%$ methomyl and $0.025 \%(\mathrm{Z})$-9-tricosene (Zoecon, Dallas, Tex.). Captured flies were examined for marks as previously described and were classified according to their origin (dairy, poultry house, or unmarked wild).

Sixty baited jug-traps were placed throughout Farm A on the day following each release. Traps were arranged in the pasture, field, and building habitats in a grid with the traps ca. $45 \mathrm{~m}$ apart. Nine traps were fastened to the outside of several buildings $1.5 \mathrm{~m}$ aboveground, 7 traps were suspended $1.5 \mathrm{~m}$ aboveground from wooden stakes in the fields, and 23 traps were placed throughout the pastures $1.5 \mathrm{~m}$ aboveground in the center of three wooden stakes surrounded with barbed wire as protection against the cattle. Three traps were suspended from the roof above the feed trough in the dairy. Since variation in fly capture occurs along the long axis of a poultry house (Burg \& Axtell 1984), three baited jug-traps were suspended from the rafters at equal intervals along the center aisle of each narrow poultry house and along each outer walkway of the wide-span poultry houses. A total of 18 traps was placed in the poultry habitat.

Forty baited jug-traps were used at Farm B. Traps in the building, field, and pasture habitats were distributed in a grid arrangement with the traps ca. $45 \mathrm{~m}$ apart. The number of traps in the building, field, and pasture habitats was 4,11 , and 
Table 1. Mean number of house flies caught per trap per 3-day sampling period in five habitats in Farm A

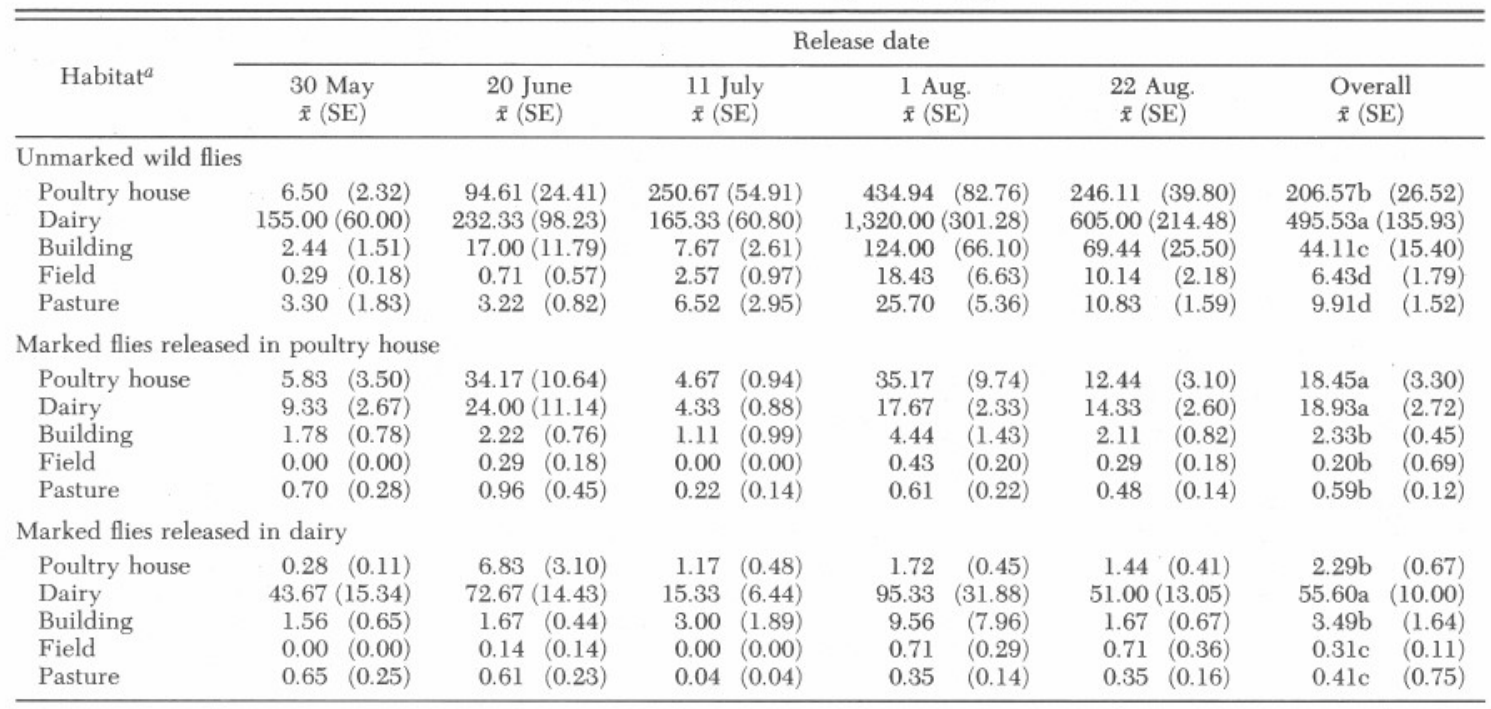

Means followed by the same letter are not significantly different $(P>0.05$; Duncan's multiple range test [SAS Institute 1982]).

${ }^{a}$ Number of traps in each habitat per sampling period were as follows: poultry, 18; dairy, 3; building, 9; field, 10 ; pasture, 23.

10 , respectively. Seven traps were placed throughout the dairy. Eight traps were placed in the poultry house, four at each end (two suspended from the rafters above the walkway, and two below the walkway).

Data Analysis. The numbers of wild and marked flies captured were transformed to $\log _{10}(x+1)$. The data were subjected to analysis of variance to determine if significant differences in relative density of flies existed between habitats. Data obtained at each farm were analyzed separately and each release/recapture period was treated as a replication. Duncan's multiple range test (SAS Institute $1982,101-110)$ was used to separate the means $(P<0.05)$.

The effect of the distance of a trap from the edge of the area in which marked flies were released on the capture of marked flies was analyzed separately for each farm and release areas within farms by fitting the data by least-squares regression to the model:

$$
y=b_{0}+b_{1}\left(x_{1}+1\right)^{-0.5}
$$

where $y=\log _{10}$ (mean number marked flies caught per trap +1$), x_{1}=$ distance of trap from the release area in meters, $b_{0}=$ intercept, and $b_{1}=$ slope. Traps inside a release area had distance equal to 0 .

Fletcher (1974) provided a method for calculating the proportion of insects released from a central release point that were in an annulus of a given distance from the release point based on the number of traps per annulus, the number of insects caught in an annulus, and the area of each annulus. This method was modified to calculate the proportion of flies in a habitat by substituting habitat area for annulus area, so that the percent of the total fly population in a given habitat can be calculated using:

$$
\hat{p}=\frac{A_{i} X_{i} / n_{i}}{\Sigma\left(A_{i} X_{i} / n_{i}\right)} \times 100
$$

where $X_{i}=$ total number of flies caught in a habitat, $n_{i}=$ the number of traps in a habitat, and $A_{i}$ $=$ area of the habitat.

\section{Results}

Relative Density of House Flies Within Habitats. The average number of flies caught per trap in each habitat during each 3-day sampling period of the experiment is shown in Table 1 (Farm A) and Table 2 (Farm B). Although the numbers of wild and marked flies caught in each habitat varied among the sampling periods, the patterns of abundance among the habitats during each of the sampling periods were fairly consistent throughout the study and were reflected in the overall average number of flies caught per trap in each habitat during the entire summer. At Farm A (Table 1), the overall average number of wild flies caught per trap per 3-day period was highest in the dairy, intermediate in the poultry house and building habitats, and lowest in the field and pastures. The average number of marked flies in the poultry house at Farm A recovered by trapping for 3 days was highest in the poultry houses and dairy, followed by the building, pasture, and field habitats. The average number of marked flies released in the dairy at Farm A recovered by trapping for 3 days was highest in the dairy, intermediate in the building and poultry habitats, and lowest in the pasture and field habitats. 
Table 2. Mean number of house flies eaught per trap per 3-day sampling period in five habitats in Farm B

\begin{tabular}{|c|c|c|c|c|c|c|c|c|c|}
\hline \multirow[b]{2}{*}{ Habitat $^{a}$} & \multicolumn{9}{|c|}{ Release date } \\
\hline & $\begin{array}{c}20 \text { June } \\
\bar{x} \text { (SE) }\end{array}$ & \multicolumn{2}{|c|}{$\begin{array}{l}11 \text { July } \\
\bar{x} \text { (SE) }\end{array}$} & \multicolumn{2}{|c|}{$\begin{array}{l}1 \text { Aug. } \\
\bar{x} \text { (SE) }\end{array}$} & \multicolumn{2}{|c|}{$\begin{array}{l}29 \text { Aug. } \\
\bar{x} \text { (SE) }\end{array}$} & \multicolumn{2}{|c|}{$\begin{array}{l}\text { Overall } \\
\bar{x}(\mathrm{SE})\end{array}$} \\
\hline \multicolumn{10}{|c|}{ Unmarked wild flies } \\
\hline $\begin{array}{l}\text { Poultry house } \\
\text { Dairy } \\
\text { Building } \\
\text { Field } \\
\text { Pasture }\end{array}$ & $\begin{array}{r}237.88(35.29) \\
84.86(23.70) \\
18.75(7.38) \\
9.91(3.74) \\
9.70(1.27)\end{array}$ & $\begin{array}{c}490.50( \\
69.71 \\
8.50 \\
7.00 \\
9.71\end{array}$ & $\begin{array}{r}125.43) \\
(16.29) \\
(3.78) \\
(3.10) \\
(3.00)\end{array}$ & $\begin{array}{c}754.25 \\
246.00 \\
51.25 \\
42.64 \\
61.10\end{array}$ & $\begin{array}{l}149.51) \\
(43.98) \\
(17.82) \\
(11.86) \\
(12.17)\end{array}$ & $\begin{array}{r}198.13 \\
63.29 \\
8.50 \\
6.27 \\
11.80\end{array}$ & $\begin{array}{r}(27.59) \\
(19.81) \\
(2.18) \\
(2.56) \\
(4.86)\end{array}$ & $\begin{array}{r}420.19 a \\
115.96 b \\
21.75 c \\
16.45 c \\
23.08 c\end{array}$ & $\begin{array}{r}(62.20) \\
(19.63) \\
(6.27) \\
(3.91) \\
(4.79)\end{array}$ \\
\hline \multicolumn{10}{|c|}{ Marked flies released in poultry house } \\
\hline $\begin{array}{l}\text { Poultry house } \\
\text { Dairy } \\
\text { Building } \\
\text { Field } \\
\text { Pasture }\end{array}$ & $\begin{array}{ll}8.50 & (2.01) \\
3.43 & (1.54) \\
1.50 & (0.87) \\
0.91 & (0.37) \\
0.40 & (0.22)\end{array}$ & $\begin{array}{r}12.88 \\
0.43 \\
0.50 \\
0.09 \\
0.30\end{array}$ & $\begin{array}{l}(2.31) \\
(0.30) \\
(0.50) \\
(0.09) \\
(0.21)\end{array}$ & $\begin{array}{r}41.38 \\
3.00 \\
4.75 \\
0.64 \\
0.30\end{array}$ & $\begin{array}{l}(6.53) \\
(1.02) \\
(2.29) \\
(0.28) \\
(0.15)\end{array}$ & $\begin{array}{r}23.25 \\
1.29 \\
1.00 \\
0.18 \\
0.30\end{array}$ & $\begin{array}{l}(8.01) \\
(0.47) \\
(0.41) \\
(0.12) \\
(0.30)\end{array}$ & $\begin{array}{r}21.50 \mathrm{a} \\
2.04 \mathrm{~b} \\
1.94 \mathrm{~b} \\
0.45 \mathrm{c} \\
0.33 \mathrm{c}\end{array}$ & $\begin{array}{l}(3.43) \\
(0.51) \\
(0.71) \\
(0.13) \\
(0.11)\end{array}$ \\
\hline \multicolumn{10}{|c|}{ Marked flies released in dairy } \\
\hline $\begin{array}{l}\text { Poultry house } \\
\text { Dairy } \\
\text { Building } \\
\text { Field } \\
\text { Pasture }\end{array}$ & $\begin{array}{rr}4.25 & (0.79) \\
11.00 & (4.17) \\
1.50 & (0.50) \\
0.27 & (0.19) \\
0.60 & (0.34)\end{array}$ & $\begin{array}{l}2.25 \\
7.57 \\
0.00 \\
0.00 \\
0.40\end{array}$ & $\begin{array}{l}(0.67) \\
(2.09) \\
(0.00) \\
(0.00) \\
(0.22)\end{array}$ & $\begin{array}{r}1.88 \\
10.14 \\
0.00 \\
0.18 \\
0.20\end{array}$ & $\begin{array}{l}(0.64) \\
(4.43) \\
(0.00) \\
(0.12) \\
(0.13)\end{array}$ & $\begin{array}{l}2.00 \\
6.00 \\
0.00 \\
0.00 \\
0.30\end{array}$ & $\begin{array}{l}(0.42) \\
(2.46) \\
(0.00) \\
(0.00) \\
(0.21)\end{array}$ & $\begin{array}{l}2.59 \mathrm{~b} \\
8.68 \mathrm{a} \\
0.38 \mathrm{c} \\
0.11 \mathrm{c} \\
0.38 \mathrm{c}\end{array}$ & $\begin{array}{l}(0.35) \\
(1.67) \\
(0.20) \\
(0.06) \\
(0.12)\end{array}$ \\
\hline
\end{tabular}

Means followed by the same letter are not significantly different $(P>0.05$; Duncan's multiple range test [SAS Institute 1982]). ${ }^{a}$ Number of traps in each habitat per sampling period were as follows: poultry, 8 ; dairy, 7 ; building, 4 ; field, 11 ; pasture, 10.

At Farm B, results were slightly different (Table 2 ). The average number of wild flies caught per trap per 3-day period was highest in the poultry house, followed by the dairy, pasture, building, and field habitats. The average number of marked flies released in the poultry house at Farm B recovered by trapping for 3 days was highest in the poultry house, intermediate in the dairy and building habitats, and lowest in the pasture and field. A significantly higher average number of marked flies released in the poultry house was recovered in the building and dairy habitats than in the pasture and field habitats. The average number of marked flies released in the dairy recovered by trapping for 3 days was highest in the dairy, followed by the poultry house, pasture, building, and field habitats.

Distance Versus Recapture. The results of the analyses are shown in Table 3 . The relationship of distance from the release area to the number of marked flies from a release area caught per trap was significant $(P<0.01)$ and acounted for $48-$ $82 \%$ of the variation in capture of marked flies. Densities of marked flies from a release area declined dramatically within the first $50 \mathrm{~m}$, but were higher in the dairies and poultry houses at both farms than in other habiats at similar distances from the release point (Fig. 1).

Proportion of Population in Each Habitat. The percent of wild and marked flies in each habitat at each farm was calculated for each release; means are shown in Table 4 . The dairy and poultry houses together contained $75 \%$ of the wild fly population at Farm $\mathrm{A}$ and $64 \%$ of the wild fly population at Farm B, even though the combined areas of these habitats composed $<14 \%$ of the total area sampled on each farm. Approximately 25 and $36 \%$ of the wild fly population were spread throughout the other habitats at Farms A and B.

Of the surviving flies that were marked and released in the poultry houses, 60 and $53 \%$ remained there at Farms A and B. Thus, 40 and $47 \%$ left the poultry houses, assuming dispersal was primarily limited to the areas sampled. Similarly, 44 and $27 \%$ of surviving flies marked and released in the dairies at Farms A and B left the dairies. At both farms, $13 \%$ of the surviving flies marked and released in the poultry houses moved to the dairies. Averages of 10 and $8 \%$ of the surviving marked flies released in the dairies at Farms A and B, respectively, had moved to the poultry houses at Farms A and B. Therefore, 27 and $34 \%$ of the marked flies released in the poultry houses moved into the building, field, and pasture habitats at Farms A and B, and 34 and 19\% of the marked flies released in the dairies moved into these habitats at Farms A and B.

\section{Discussion}

The relative density of wild flies and flies moving from one breeding area to another was related to the sanitation level of each habitat. The poultry houses and dairies containing accumulated animal manure had the highest relative density of wild flies as well as released flies at both farms. The relative density of wild and released flies was lowest in the pasture and field habitats where manure was either dispersed or absent. The presence of house flies in the building habitats was perhaps due to their proximity to the breeding areas on both farms.

In uniform areas, distance from a release point and density of insects have been shown to be re- 
Table 3. Relationship between density and distance (m) from release area of marked flies released in dairies and poultry houses

\begin{tabular}{lcccc}
\hline \hline Release area & $n$ & $\begin{array}{c}b_{0} \\
\text { intercept }\end{array}$ & $\begin{array}{c}b_{1} \\
\text { distance }(\mathrm{m})\end{array}$ & $r^{2}$ \\
\hline Farm A & & & & \\
$\quad$ Poultry house & 60 & 0.202 & $1.356(0.185)$ & 0.48 \\
$\quad$ Dairy & 60 & 0.096 & $1.540(0.187)$ & 0.54 \\
Farm B & & & & \\
$\quad$ Poultry house & 40 & 0.069 & $1.248(0.093)$ & 0.82 \\
$\quad$ Dairy & 40 & 0.125 & $0.926(0.150)$ & 0.52 \\
\hline
\end{tabular}

All parameters are significant $(P>0.05$; PROC REG [SAS Institute 1982]). Numbers in parentheses are SE of estimates.

lated for a variety of species (Taylor 1978) including the house fly (based on data in Parker [1916]). However, farms are not uniform areas. In the case of the house fly, sanitation is a major factor in movement of house flies to an area because poor sanitation is related to the availability of food and breeding sites (Quarterman et al. 1954a,b, Morris \& Hansen 1966, Oda 1966, Pickens et al. 1967). In our experiment, the average number of flies caught per trap per 3-day period declined dramatically within the first $50 \mathrm{~m}$ from the release areas (poultry houses and dairies), but unsanitary sites such as the poultry houses and dairies were preferred areas for fly congregation, as indicated by the high relative density of house flies in these areas. The building habitat appeared as attractive as the poultry houses to flies moving out of the dairy at Farm A, probably because the buildings were directly between the poultry houses and dairy and acted as a resting site for flies moving out of the dairy to the poultry houses. The buildings at Farm B were not directly between the poultry house and the dairy and were less likely to act as resting sites for flies moving out of these habitats.

Although the density of wild flies was lowest in the building, field, and pasture habitats, these habitats made up a large proportion of the total areas of Farms A and B (86 and 87\%, respectively) and were estimated to contain 25 and $36 \%$ of the wild fly populations in both farms. Since these habitats are not likely to receive insecticide treatment, they can be regarded as refugia and the segment of the fly population that is in these habitats will not be subjected to insecticide pressure unless they move to a treated area. Similarly, although the density of marked flies decreased dramatically within $50 \mathrm{~m}$ of the area in which the flies were released, the release sites accounted for $<14 \%$ of the total area of each farm. The average percent of marked flies released in an area and then left were $40,47,44$, and $27 \%$ of the marked flies released in the poultry houses at Farms A and B and the dairies at Farms $\mathrm{A}$ and $\mathrm{B}$, respectively. Although the density of marked flies outside the release areas was low, a substantial proportion of the marked flies released in each breeding site had left the release areas. The average proportion of

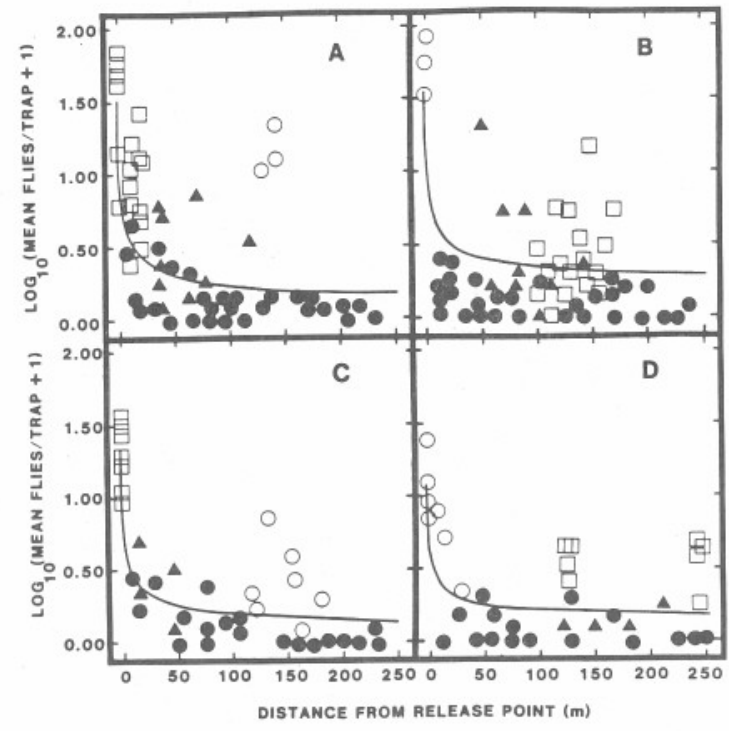

Fig. 1. Relationship between density and distance from release area of marked flies released in (A) poultry house, Farm A; (B) dairy, Farm A; (C) poultry house, Farm B; (D) dairy, Farm B. Solid lines are the relationship between density and distance from release point determined by least-squares regression (Table 3). Habitats in which traps were placed: $\square$, poultry house; $O$, dairy; field, pasture; $\boldsymbol{\Delta}$, building.

marked flies released in a breeding area that moved to another breeding site ranged from 8 to $13 \%$ of the surviving marked flies released. If different insecticides are applied at the different breeding areas within a farm, or, if insecticides are applied in only one breeding area, this movement between breeding sites could represent an influx of susceptible individuals to the destination breeding site, particularly if the number of incoming flies is large

Table 4. Average percent of wild and marked fly populations in each habitat ealculated using a modification of Fleteher's (1974) formula

\begin{tabular}{|c|c|c|c|}
\hline Habitat & $\begin{array}{c}\text { Wild flies } \\
\bar{x}(\mathrm{SE})\end{array}$ & $\begin{array}{l}\text { Marked flies } \\
\text { released in } \\
\text { poultry house } \\
\bar{x} \text { (SE) }\end{array}$ & $\begin{array}{l}\text { Marked flies } \\
\text { released in } \\
\text { dairy } \\
\bar{x}(\mathrm{SE})\end{array}$ \\
\hline \multicolumn{4}{|l|}{$\overline{\text { Farm A }}{ }^{a}$} \\
\hline Poultry house & $44(10)$ & $60 \quad(5)$ & $10(4)$ \\
\hline Dairy & $31 \quad(8)$ & 13 (1) & $56(5)$ \\
\hline Building & 12 (3) & $15 \quad(2)$ & $23(7)$ \\
\hline Field & $2(1)$ & 1 (1) & $3(2)$ \\
\hline Pasture & $11(3)$ & 11 (3) & $8(3)$ \\
\hline \multicolumn{4}{|l|}{ Farm $\mathbf{B}^{b}$} \\
\hline Poultry house & $38(6)$ & $53(10)$ & $8(1)$ \\
\hline Dairy & $26 \quad(2)$ & $13(4)$ & $73(4)$ \\
\hline Building & $6(1)$ & $13(3)$ & $3(3)$ \\
\hline Field & $11(2)$ & $11(5)$ & $2(1)$ \\
\hline Pasture & $19(3)$ & 11 (3) & $14(2)$ \\
\hline
\end{tabular}

${ }^{a}$ Five observations per mean at Farm A.

${ }^{b}$ Four observations per mean at Farm B. 
relative to the numbers already present in the destination breeding site.

Development of resistance to insecticides can be delayed if short-lived sprays are used (Denholm et al. 1983) and movement of susceptible individuals into breeding areas occurs to dilute the resistant gene pool (Georghiou \& Taylor 1977b). Susceptible house flies may be available from untreated areas such as the building, field, and pasture habitats, but movement from these habitats back into breeding areas has not been documented. Susceptible individuals may be available from other breeding areas provided that the same selection pressure is not applied to all breeding areas on the same farm. This may mean treatment only when necessary with short-lived compounds and use of dissimilar insecticides between breeding sites within a farm. Movement between breeding sites also means that recolonization of a potential breeding site after control measures have been relaxed is possible, emphasizing the need for sound management practices (such as sanitation) in all potential breeding areas within a farm.

\section{Acknowledgment}

This is Paper No. 10195 of the Journal Series of the N.C. Agric. Res. Serv., Raleigh.

\section{References Cited}

Axtell, R. C. 1970. Integrated fly-control program for caged-poultry houses. J. Econ. Entomol. 63: 400-405.

Bishopp, F. C. \& E. W. Laake. 1919. The dispersion of flies by flight. J. Econ. Entomol. 12: 210-211.

Burg, J. G. \& R. C. Axtell. 1984. Monitoring house fly (Musca domestica) (Diptera: Muscidae) populations in caged layer poultry houses using a baited jug-trap. Environ. Entomol. 13: 1083-1090.

Denholm, I., A. W. Farnham, K. O'Dell \& R. M. Sawicki. 1983. Factors affecting resistance to insecticides in house flies, Musca domestica L. (Diptera: Muscidae). I. Long-term control with bioresmethrin of flies with strong pyrethroid-resistance potential. Bull. Entomol. Res. 73: 481-489.

Fletcher, B. S. 1974. The ecology of a natural population of the Queensland fruit fly, Dacus tyronii V. The dispersal of adults. Aust. J. Zool. 22: 189-202.

Georghiou, G. P. \& C. E. Taylor. 1977a. Genetic and biological influences in the evolution of insecticide resistance. J. Econ. Entomol. 70: 319-323.

$1977 \mathrm{~b}$. Operational influences in the evolution of insecticide resistance. J. Econ. Entomol. 70: 653-658.

Hanec, W. 1956. A study of the environmental factors affecting the dispersion of house flies (Musca domestica L.) in a dairy community near Fort Whyte, Manitoba. Can. Entomol. 88: 270-272.

Lindquist, A. W., W. W. Yates \& R. A. Hoffman. 1951.
Studies of the flight habits of three species of flies tagged with radioactive phosphorus. J. Econ. Entomol. 44: 397-400.

MacDonald, R. S., G. A. Surgeoner, K. R. Solomon \& C. R. Harris. 1983. Development of resistance to permethrin and dichlorvos by the house fly (Diptera: Muscidae) following continuous and alternating insecticide use on four farms. Can. Entomol. 115: 15551561.

Morris, A. P. \& E. J. Hansen. 1966. Dispersion of insecticide resistant populations of the house fly, Musca domestica L. J. Econ. Entomol. 59: 45-50.

Oda, T. 1966. Studies on the dispersal of the house fly Musca domestica vicina by mark and release method. Endem. Dis. Bull. Nagasaki Univ. 8: 136144.

Parker, R. R. 1916. Dispersion of Musca domestica L. under city conditions in Montana. J. Econ. Entomol. 9: 325-354.

Peffly, R. L. \& G. C. LaBrecque. 1956. Marking and trapping studies on dispersal and abundance of Egyptian house flies. J. Econ. Entomol. 49: 214-217.

Pickens, L. G., N. O. Morgan, J. G. Hartstock \& J. W. Smith. 1967. Dispersal patterns and populations of the house fly affected by sanitation and weather in rural Maryland. J. Econ. Entomol. 60: 1250-1255.

Quarterman, K. D., W. Mathis \& J. W. Kilpatrick. 1954a. Urban fly dispersal in the area of Savannah, Georgia. J. Econ. Entomol. 47: 405-412.

1954b. Fly dispersal in a rural area near Savannah, Georgia. J. Econ. Entomol. 47: 413-419.

Ranade, D. R. 1956. Some observations on the range of flight of the common Indian house fly, Musca domestica nebulo Fabr. J. Anim. Morphol. Physiol. 3: 104-108.

SAS Institute. 1982. SAS user's guide: statistics. SAS Institute, Cary, N.C.

Schoof, H. F. \& R. E. Siverly. 1954a. Urban fly dispersal with special reference to movement pattern of Musca domestica. Am. J. Trop. Med. Hyg. 3: 539547.

1954b. Multiple release studies on the dispersion of Musca domestica at Phoenix, Arizona. J. Econ. Entomol. 47: 830-838.

Schoof, H. F., R. E. Siverly \& J. A. Jensen. 1952. House fly dispersion studies in metropolitan areas. J. Econ. Entomol. 45: 675-683.

Tabashnik, B. E. \& B. A. Croft. 1982. Managing pesticide resistance in crop-arthropod complexes: interactions between biological and operational factors. Environ. Entomol. 11: 1137-1144.

Taylor, R. A. J. 1978. The relationship between density and distance of dispersing insects. Ecol. Entomol. 3: 63-70.

Wada, Y. \& T. Oda. 1963. On the range and the number in the dispersal of the housefly, Musca domestica vicina, around hog houses. Endem. Dis. Bull. Nagasaki Univ. 5: 116-122.

Received for publication 22 November 1985; accepted 12 March 1986. 